(C) 2021, The Authors. Published by Elsevier Inc. and Fass Inc. on behalf of the American Dairy Science Association ${ }^{\circledR}$. This is an open access article under the CC BY-NC-ND license (http://creativecommons.org/licenses/by-nc-nd/4.0/).

\title{
Genetic parameters of hair cortisol as an indicator of chronic stress under different environments in Holstein cows
}

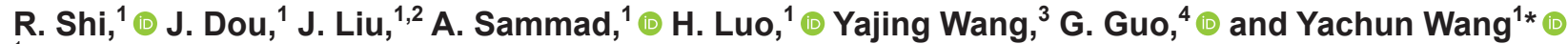 \\ ${ }^{1}$ Key Laboratory of Animal Genetics, Breeding and Reproduction, MARA, National Engineering Laboratory of Animal Breeding, \\ College of Animal Science and Technology, China Agricultural University, Beijing 100193, China \\ ${ }^{2}$ State Key Laboratory of Animal Nutrition, Institute of Animal Science, Chinese Academy of Agricultural Sciences, Beijing 100193, China \\ ${ }^{3}$ State Key Laboratory of Animal Nutrition, College of Animal Science and Technology, China Agricultural University, Beijing 100193, China \\ ${ }^{4}$ Beijing Sunlon Livestock Development Co. Ltd., Beijing 100176, China
}

\begin{abstract}
Chronic stress is a risk factor for a variety of physiological disorders because of its increased activation of the hypothalamic-pituitary-adrenal (HPA) axis; however, it is difficult to reveal environmental and genetic effects contributing to long-term HPA activity because of the complexity of chronic stress. The hair cortisol concentration (HCC) can be used to reflect the accumulation of HPA axis activity over time. Some studies suggest that the HCC might be associated with the protein concentration $(\mathrm{PC})$ in the hair shaft; however, no studies have revealed a dynamic relationship between them. In the present study, 1,086 hair samples from 418 Holstein cows were collected, and the effects of environmental factors on HCC, PC, and ratio of HCC to PC (HCCP) were studied. Subsequently, regression analysis and curve fitting were used to identify for better-performing indicators of chronic stress. Additionally, univariate and bivariate genetic evaluation were used to estimate the genetic components of cortisol traits and genotype by environment interactions $(\mathrm{G} \times \mathrm{E})$ under different environmental and physiological states. The results showed that HCC and PC are significantly affected by hair color, sampling year, and season, whereas HCCP is not influenced by hair color. Adjusted PC and HCCP, where confounding effects are excluded, were moderately related with chronic stress indicators. Moderate to high heritabilities were obtained for HCC $(0.347$ and 0.390 for winter and summer, respectively), PC (0.402 and 0.495 for winter and summer, respectively) and HCCP (0.289 and 0.460 for winter and summer, respectively) when animals in the same season were evaluated. A moderate $\mathrm{G} \times \mathrm{E}$ interaction was detected in this study, as indicated by
\end{abstract}

Received November 5, 2019.

Accepted February 9, 2021.

*Corresponding author: wangyachun@cau.edu.cn the low or negative genetic correlation for the same cortisol trait in different environments (e.g. heat stress condition and thermoneutral condition). In conclusion, HCCP is not affected by hair color compared with the other 2 traits; thus, it has potential as an indicator of chronic stress. Hair cortisol traits could monitor stress response process in cattle, as well as provide a better understanding of genetic mechanism for long-term HPA activity.

Key words: hair cortisol, chronic stress, genetic analysis, genotype by environment interaction

\section{INTRODUCTION}

A stress reaction occurs when the body of an animal makes adaptive responses to strong challenges (stressors), which activates the hypothalamic-pituitaryadrenal (HPA) axis, together with an increase in the cortisol concentration (Tiwari et al., 2015). Stress can be classified as acute stress or chronic stress based on the persistency of stressors, and the chronic activation of the HPA axis is a risk factor for an impaired immune system and reproductive function in animals (Matteri et al., 2000; Chrousos, 2009). A major stressor affecting animal husbandry is environmental heat. Studies have shown that high temperature conditions can lead to a decrease in milk production (Ravagnolo et al., 2000; Lambertz et al., 2014) and feed intake (West et al., 2003). In the United States, the annual economic losses caused by heat have been reported to be $\$ 1,690$ million to $\$ 2,360$ million, with $58 \%$ of these losses coming from the dairy industry (Stpierre et al., 2003).

Investigations of physiological responses to stress routinely use cortisol as an indicator of the activity of the HPA axis. In cattle, cortisol has been widely measured in blood, saliva, feces, and usrine (Burnard et al., 2017). However, assessing the cortisol in blood requires invasive sampling methods that would change the physiological status of the cows instantly. Additionally, the cortisol concentration in blood might be highly 
variable because of the complex components of plasma (Forslund et al., 2010). Preceding feed or water intake may interfere saliva sampling by increased salivation or contamination (e.g., oil and additives) with food (Bautista et al., 2019), which may increase analytical noise and contribute to incorrect test results. The collection of urine is minimally invasive, but it is not practicable in animals (Bautista et al., 2019). Furthermore, cortisol in feces is not dependable as chronic stress indicator because of the highly different microbiome composition in the digestive organs, and it can only reflect the cortisol level 10 to $12 \mathrm{~h}$ before sample collection (Möstl et al., 2002; Huzzey et al., 2011). The potential advantages of the hair cortisol concentration (HCC) to assess of chronic stress have been illustrated well in a previous study (Russell et al., 2012). The use of hair has been not only proposed to monitor chronic stress in humans (Meyer and Novak, 2012; Russell et al., 2012), but also as a noninvasive indicator of animal's endocrine response to environment and physiological stress (Aoki Cerri et al., 2012; Moya et al., 2013). Several publications have suggested that hair color, pregnancy stage, clinical status (Comin et al., 2013), and the external environment, such as rearing conditions and temperature (Comin et al., 2011; Uetake et al., 2017), are potential factors affecting the HCC in livestock.

The precise mechanism whereby cortisol enters the hair shaft is not fully determined because of the complexity of the hair structure. One of the potential mechanisms is that circulating cortisol in plasma might enter the follicle through the neighboring extracellular fluid, whereas the majority of circulating cortisol is bound to cortisol-binding globulin, which must be decoupled before being transferred to other tissues (Ralph and Tilbrook, 2016). The cortisol within the follicle would presumably bind the receptor protein to participate in the keratinization process. The migrating bulb cells in the follicle, which carry receptor-bound cortisol, undergo terminal differentiation into keratinocytes, such that cortisol is trapped within the hardening cuticle (Burnard et al., 2017). During this process, melanocytes produce melanin pigments in melanosomes, which penetrate surrounding keratinocytes to embed pigment in the hair shaft, thus determining hair color (Pragst and Balikova, 2006). Based on these mechanisms, we assumed that the amount of proteins would vary between black and white hair from dairy cattle, and it might be the reason why different levels of HCC were observed in different colored hair.

In Beijing (China), dairy cows experience severe heat from June to September, with average daily temperature-humidity index (THI) exceeding 68 (Figure 1), and this long-term heat stress can be treated as chronic stress. Seasonal effects suggested by many authors could confound other environment effects and result in inexplicable estimates (Uetake et al., 2017). Meanwhile, studies have shown that the HCC fluctuates during the course of pregnancy, which is also a long-term chronic stress for female cattle. To the best of our knowledge, only one study has demonstrated the effect of pregnancy status on the concentration of hair cortisol in cattle. Burnett et al. (2015) measured hair cortisol for $126 \mathrm{~d}$ during the pregnancy cycle using 64 individuals. However, no research has illustrated an association between the dynamic changes in HCC and the protein concentration (PC) in hair over time. According to the mechanisms of hair construction and pigmentation (Pragst and Balikova, 2006; Burnard et al., 2017), the HCC might correlate with the number of receptors and the melanin pigments in the hair shaft, both of which are proteins. Thus, a novel trait, the ratio of $\mathrm{HCC}$ to $\mathrm{PC}$ (HCCP), which accounts for the relationship between HCC and PC, was included in this paper. For genetic parameters of hair cortisol traits, published assessments from vervet monkeys indicated relatively high heritabilities (0.31) in different environments (Fairbanks et al., 2011); however, there has been no research done to evaluate the genetic parameters of hair cortisol in cattle.

The objective of current study was to determine the associations between 3 hair cortisol traits (HCC, PC, and HCCP) with sampling year, sampling season, and hair color in dairy cows. Furthermore, we aimed to find a reliable indicator that could monitor heat stress and reveal the dynamic relationship between hair cortisol traits and the pregnant status of cows. Finally, we estimated the genetic parameters of hair cortisol traits under various environments to demonstrate how the HPA axis responds genetically under different circumstances.

\section{MATERIALS AND METHODS}

\section{Data Collection}

Animals. Holstein dairy cows $(\mathrm{n}=418)$ were used in the current study between July 2014 and January 2016 at a farm of the Sunlon Livestock Development Co. Ltd. in Beijing, China. All animals were housed in the same ventilated barn with a freestall design and were milked 3 times/d at 0700, 1400, and $2100 \mathrm{~h}$ using automatic milking machines. The TMR was delivered 3 times daily, and the animals had ad libitum access to TMR and water. The cooling system (fans and sprinklers) in the barn operated during the summer (from June to September).

Information about parents were provided by the company, and test-day records of the experiment animals were obtained using Afifarm software (https://www 


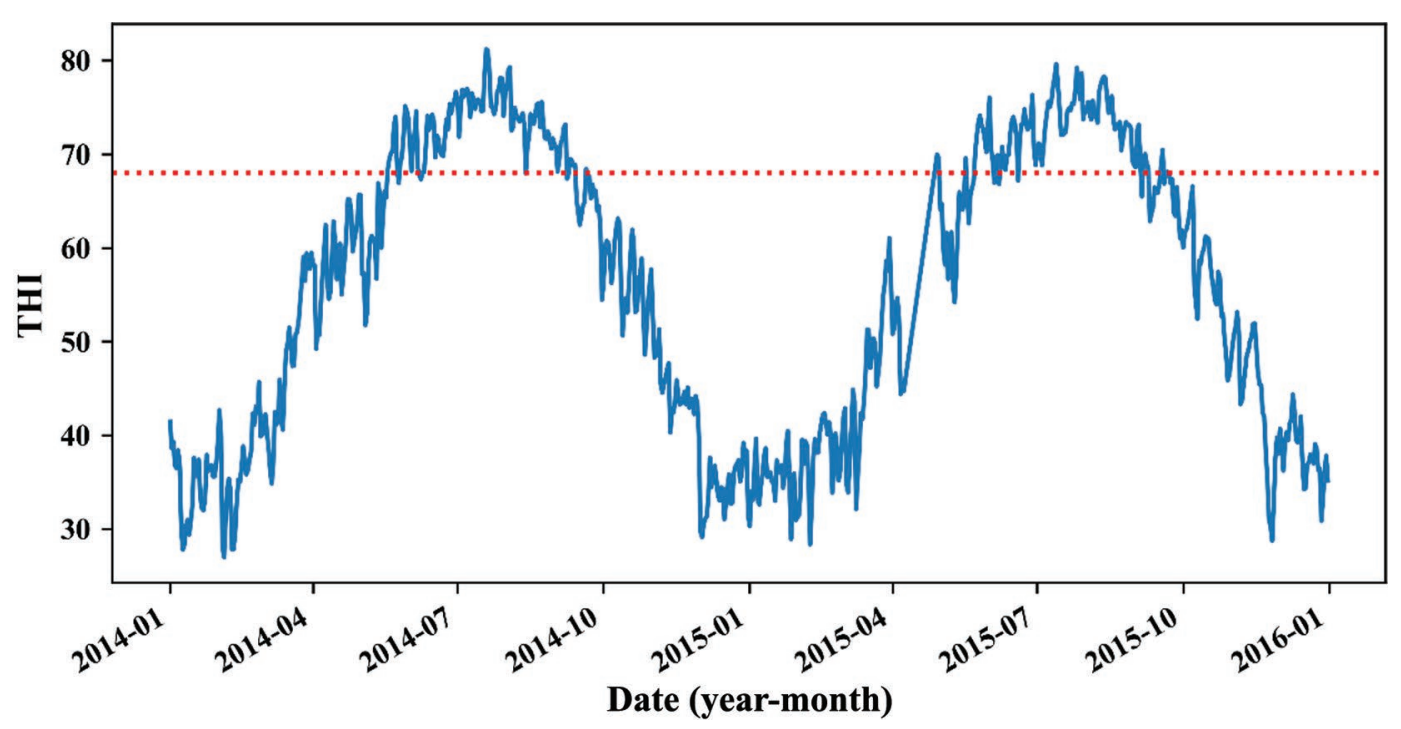

Figure 1. Temperature-humidity index (THI) curve of Beijing during the experiment years. The red horizontal line indicates a THI of 68 . The data used for this curve were provided by the nearest weather station from the experiment farm.

.afimilk.com.cn). Each sampled animal was traced at least 3 generations back to construct pedigree. Ultimately, the pedigree included 741 sires and 2,169 cows. For milk yield, only the data from 2015 summer was provided, and records from $30 \mathrm{~d}$ before the sampling day of each individual were also matched. Other ordinary herd data such as parity and DIM were also measured in this study, and DIM grouped by week (DIM_W) was calculated for further analysis.

Meteorological Data and Heat Stress Indicators. The temperature and humidity data were obtained from National Meteorological Information Center (http://data.cma.cn/). All the statistics were recorded hourly, and the data of nearest station, which is $15.3 \mathrm{~km}$ from the farm, were selected for analysis. Both the farm and weather station are in the south rural area of Beijing, about $25 \mathrm{~km}$ from the urbanized area. The climate data of the $30 \mathrm{~d}$ before each sampling day were kept, and daily average THI, daily maximum temperature-humidity index (THI_M), daily minimum temperature-humidity index (THI_m), and daily temperature difference (TEM_df, calculated by subtracting daily minimum temperature from daily maximum temperature) were obtained. The THI was calculated following the formula from Herbut and Angrecka $(2012), \mathrm{THI}=0.81 \times \mathrm{T}_{\mathrm{d}}+\left(0.99 \times \mathrm{T}_{\mathrm{d}}-14.3\right) \times$ $\mathrm{RH}+46.3$, where $\mathrm{T}_{\mathrm{d}}$ is the temperature in degrees Celsius of the environment and $\mathrm{RH}$ is the relative humidity (\%) of the environment. Afterward, these heat stress indicators were matched with phenotypes (HCC, PC, and HCCP; i.e., each phenotype had records of THI, THI_M, THI_m, and TEM_df for the same $30 \mathrm{~d}$ ).
Pregnancy Stress Indicators. To analyze pregnancy stress, pregnancy stage was further grouped based on DIM_W, where DIM_W $\leq 10$ or DIM_W $\geq$ 40 were classified as stress-stage groups, and DIM_W between 11 and 39 were classified as the nonstress-stage group. The division of subsets was performed according to the finding that calving has delayed effects on the HCC (Burnett et al., 2015).

Hair Sampling. Hair samples $(\mathrm{n}=1,086)$ were obtained in July (summer), November (autumn), and January (winter) of 2014 and 2015, respectively, and electric clippers (RIWA X9, RIWA Electric Company) were used to collect hair samples from the rear belly of the cows (Figure 2). The hair was clipped as near the scalp as possible and 2 types pigmented hair were collected if both colors appeared in the sampling area. Hair samples in autumn and winter were stored in a dry carton shaded from light, and in summer, samples were dampened using sprinkles and stored at $-20^{\circ} \mathrm{C}$ until further measurements. Among the 418 animals, 86 of them had only one hair sample, 20 animals were sampled at least 6 times, and 312 animals were sampled between 2 and 5 times.

Hair Cortisol Determination. The basic methods used in this study were modified and improved from the procedures suggested by Davenport et al. (2006). To extract endogenous cortisol efficiently and accurately, the incubation time and temperature used were those referred to by Thomson et al. (2010).

In preparation for the analysis, 300-mg hair samples were weighed and washed twice in two $10-\mathrm{mL}$ washes of isopropanol for 5 and 3 min each at $37^{\circ} \mathrm{C}$ in an os- 
cillator at a frequency of 240 shakes/min (tubes were changed after the first wash). Afterward, the hair samples were moved to new tubes without covers and placed in a dryer at $70^{\circ} \mathrm{C}$ for $4 \mathrm{~h}$. Once the drying process was finished, $150 \mathrm{mg}$ of dried samples were weighted accurately in 5 -mL centrifuge tubes and then fully cut (to less than $2 \mathrm{~mm}$ ) using a pair of surgical scissors. Three stainless steel balls with a diameter of $0.75 \mathrm{~cm}$ were placed in the top, middle, and bottom of the tubes, and the tubes were transferred to a stainless steel milling cup, which was prefrozen using liquid nitrogen. Grinding then took place in a ball mill for 5 min at a frequency of 35 repetitions/s. Three milliliters of methanol were added to each powdered sample, and the tubes were incubated in a hybridization oven at $50^{\circ} \mathrm{C}$ for $16 \mathrm{~h}$. Finally, the tubes were centrifuged at $1,500 \times g$ at room temperature for $5 \mathrm{~min}$, and $2 \mathrm{~mL}$ of the supernatant fraction was stored in new tubes at $-20^{\circ} \mathrm{C}$ until analysis.

The HCC was determined using a radioimmunoassay method described by Tamanini et al. (1983). Intra-assay and interassay variation coefficients were $14.39 \%$ and $17.55 \%$, respectively. For the hair PC, the bicinchoninic acid method described by Smith et al. (1985) was used, and the coefficients of variation were 6.45 and $14.59 \%$, respectively. $\mathrm{HCCP}$ was obtained by dividing $\mathrm{HCC}$ by PC.

\section{Data Analysis}

Fixed Effects Estimation. All the matched data (n $=1,086)$ were used in fixed effects estimations. Analysis of variance was applied using the SAS software (version

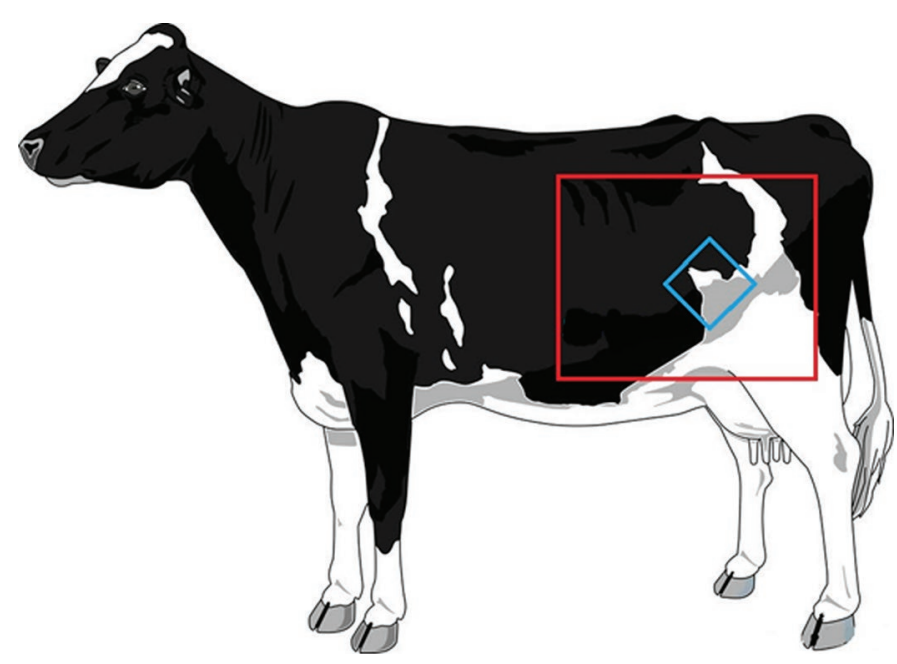

Figure 2. Hair sampling area of cows. The red rectangle indicates where to shave the hair, and the blue rectangle shows that hair of both colors should be collected for this individual.
9.4; SAS Institute) to test the significance of nongenetic effects. Sampling year, season, year and season interaction, parity, and hair color were included for all 3 traits (HCC, HCCP, and PC). In this study, parities of cows were divided into 2 levels, 1 and $\geq 2$, where the second level included cows from parity 2 to parity 9 .

Analysis of Pregnancy Stress and Hair Cortisol Traits. To obtain the relationship between pregnancy status and hair cortisol traits, all phenotypes were first adjusted by subtracting corresponding least squares means $(\mathbf{L S M})$ of significant $(P<0.05)$ nongenetic effects obtained from ANOVA. The adjusted phenotypes of 3 traits (aHCC1, aPC1, and aHCCP1) were grouped by DIM_W, and scatter plots of the average values of adjusted phenotypes during 50 wk after calving were drawn. Additionally, polynomial functions were applied to fit the most reasonable curve to the data points to show actual trends of concentration changes during pregnancy. In this analysis, the input values were DIM_W, and the weekly average values of the adjusted cortisol traits; the fitted values were calculated to draw the curve. The fitted values obtained from the polynomial functions were treated as predicted values and the models can be expressed as:

$$
\hat{y}=\sum_{1}^{n} \mathrm{DIM}_{-} \mathrm{W}^{n},
$$

where $\hat{y}$ is the fitted values of aHCC1, aPC1 and aHCCP1, DIM_W is DIM grouped by week, and $n$ is the degree of polynomial functions. Together with the true data points, the coefficient of determination $\left(\mathrm{R}^{2}\right)$ of the fit curve was calculated using this formula:

$$
\mathrm{R}^{2}=1-\frac{\sum_{i=1}^{n}\left(y_{i}-\hat{y}_{i}\right)^{2}}{\sum_{i=1}^{n}\left(y_{i}-\bar{y}_{i}\right)^{2}},
$$

where $y_{i}$ indicates the true value, $\hat{y}_{i}$ indicates the predicted value, and $\bar{y}_{i}$ indicates the average predicted value.

A total of 8 polynomial functions (degree $=1$ to 8 ) were tested in this section. To avoid under fitting or overfitting, a model with the appropriate complexity was found based on a balance between bias and variance (Lever et al., 2016). This method could be described as follow:

(1) The data set was randomly sampled into a training set $(\mathrm{n}=724)$ and test set $(\mathrm{n}=362)$ for each trait and degree. (2) A polynomial model with specific degree was first developed using the training set. (3) The bias was obtained by calculating the root mean square 
error (RMSE) between predicted values of training set and true values in training set. (4) The variance was obtained by calculating the RMSE between predicted values of test set and true values in test set. After a round, these 4 steps were repeated until 5 values for bias and variance were obtained (5-fold cross validation). Finally, an appropriate polynomial model, which generated the least average RMSE of both bias and variance, was chosen for curve fitting.

Predicting Hair Cortisol Traits Using Heat Stress Indicators. In this part, linear regression predictive models incorporating heat stress covariates will be developed and evaluated to justify the relationship of heat stress and adjusted hair cortisol traits. Similarly, to exclude the effects of other fixed factors, phenotypes were adjusted using the LSM of all nongenetic effects except for season (aHCC2, aPC2, and aHCCP2). Then, THI, THI_M, THI_m, and TEM_df of $30 \mathrm{~d}$ before sampling (marked as -1 to -30 ) were separately included in the regression models to minimize multicollinearity.

$$
y=\sum_{1}^{n} b_{n} H S_{n}
$$

$y$ are $\mathrm{aHCC} 2, \mathrm{aPC} 2$, and $\mathrm{aHCCP} 2, n$ is the number of days before the sampling day, $H S_{n}$ is heat stress indicators (THI, THI_M, THI_m, or TEM_df) at the $n$th day before the sampling day and $b_{n}$ is the regression coefficient of the heat stress indicator at the $n$th day before the sampling day. Forward stepwise selection was used to select suitable covariates (Freedman et al., 1992), and Akaike's information criterion (AIC) was used as an indicator of model fitness (Akaike, 1975). Additional covariates were kept in the model only when they caused a reduction of the AIC (threshold: reduction greater than 1; Venables and Ripley, 2002). Then, the final models incorporating heat stress indicators of specific days were developed to predict the adjusted phenotypes of cortisol traits.

After this step, the data set was randomly separated into a training set $(\mathrm{n}=724)$ and test set $(\mathrm{n}=362)$. The training set was used to develop the prediction model, i.e., to calculate the coefficients for indictors of specific days in 4 covariates (THI, THI_M, THI_m, and TEM_df) with the target of adjusted phenotypes. The test set was used to validate the accuracy of trained model (i.e., to calculate the predicted values of aHCC2, aPC2 and aHCCP2 using the covariates in the test set and the model obtained from training set. The accuracy $\left(\mathrm{R}^{2}\right)$ was calculated using predicted values and true values in the test set. The model-building and validation steps were repeated for 5 times with different random sampling seeds (5-fold cross validation). Finally, the average $\mathrm{R}^{2}$ of the prediction models was obtained for each model.

To further demonstrate the relationship between cortisol traits and heat stress, daily average milk production and THI data before $30 \mathrm{~d}$ (marked as -1 to -30) of sampling in the summer of 2015 were matched with the adjusted phenotypes. Pearson correlation coefficients among average milk production, THI, and adjusted hair cortisol traits were calculated.

Genetic Analysis. Three different analysis were carried out for these 3 hair cortisol traits, and the subsets of data were all derived from the whole data set. The first part was to evaluate general genetic parameters. Individuals with both black and white hair records (at least one record for each color) in at least one sampling season were retained. After quality control, 865 records of 332 animals remained. The records of black and white hair were 550 and 315, respectively. Furthermore, these records were evenly distributed in different seasons $(299,285$, and 281 for summer, autumn and winter, respectively) and years (433 and 432 for 2014 and 2015, respectively). Variance components were obtained using a repeatability model.

The second part was analysis of genotype by environment interaction $(\mathbf{G} \times \mathbf{E})$ for the 3 cortisol traits under normal and stressful pregnancy stages. All the records were initially divided into a stress-stage (DIM_W $\leq$ 10 or DIM_W $\geq 40$ ) and a nonstress-stage (DIM_W between 11 and 39). Then, 4 year-stage groups (2014 stress-stage, 2014 nonstress-stage, 2015 stress-stage, and 2015 nonstress-stage) were further split. Animals with only one record in at least 2 groups (e.g., an animal had one record in 2014 stress-stage group and another record in 2015 nonstress-stage group) were kept. Finally, 553 records (339 in nonstress environment vs. 214 in stress environment) were selected for each trait after quality control, with 135 overlapping animals in both environments.

In the third part, we estimated $\mathrm{G} \times \mathrm{E}$ in extreme weather conditions; thus, the data in autumn were excluded from the whole data set. Similarly, data were split into 4 year-season groups (2014 summer, 2014 winter, 2015 summer, and 2015 winter). Qualified individuals must have only one record in at least 2 groups (e.g., an animal had one record in 2014 summer group and another record in 2015 winter group). Therefore, 237 records (117 vs. 120) with 82 overlapping animals were retained in this evaluation.

Heritabilities and genetic correlations were estimated using a repeatability model [1] or an animal model [2 or 3] by average-information REML implemented in DMU software (Madsen and Jensen, 2006). The $G \times$ $\mathrm{E}$ was assessed using a bivariate form of the model $[2$ 
or 3], where hair cortisol variables were considered as 2 different traits in different environments, and genetic correlation was used to indicate the magnitude of $\mathrm{G}$ $\times \mathrm{E}$ (Falconer and Mackay, 1996). The $\mathrm{G} \times \mathrm{E}$ would be statistically significant if the genetic correlation between 2 traits (the same trait measured in different environments) was significantly different from unity using one-tailed $t$-test with a significance level set at 0.05 (Ismael et al., 2016).

The models are shown below. The univariate form of Model 1 was used to estimate general variance components for the 3 traits, whereas genetic correlations among the 3 traits were obtained using the bivariate form of the Model 1. Pregnancy effects (related to DIM) were excluded in Model 2, which was used to evaluate genetic parameters under normal and stressful pregnancy stages. Model 3] could generate genetic parameters among different seasons because the season effect was not incorporated.

$$
\begin{gathered}
\mathrm{y}_{\mathrm{ijkl}}=\mathrm{YS}_{\mathrm{i}}+\text { color }_{\mathrm{j}}+\text { DIM_W }_{\mathrm{k}},+ \text { animal }_{\mathrm{ijkl}} \\
+ \text { pe }_{\mathrm{ijkl}}+\mathrm{e}_{\mathrm{ijkl}}, \\
\mathrm{y}_{\mathrm{ij}}=\mathrm{YS}_{\mathrm{i}}+\text { color }_{\mathrm{j}}+\text { animal }_{\mathrm{ij}}+\mathrm{e}_{\mathrm{ij}}, \\
\mathrm{y}_{\mathrm{ijk}}=\text { year }_{\mathrm{i}}+\text { color }_{\mathrm{j}}+\text { DIM_g }_{\mathrm{k}}+\text { animal }_{\mathrm{ijk}}+\mathrm{e}_{\mathrm{ijk}},[3]
\end{gathered}
$$

where $\mathrm{y}$ is the phenotypic trait, YS is a fixed effect of combining the sampling year and season, color is a fixed effect of hair color, DIM_W is a fixed effect of days in milk of week, DIM_g is a fixed effect of the pregnant group (DIM_W $\leq 10$ or DIM_W $\geq 40$ were recoded as 1; DIM_W between 11 and 39 was recorded as 2), animal is random animal additive genetic effect, pe is random permanent environmental effect, and e is random residual effect. For HCCP, the color effect was removed, because HCCP was not affected by hair color according to the results of ANOVA. For the bivariate models, it is assumed that

$$
\left[\begin{array}{l}
\mathrm{a}_{1} \\
\mathrm{a}_{2}
\end{array}\right] \sim N\left(0, \mathbf{A} \otimes\left[\begin{array}{cc}
\sigma_{\mathrm{a}_{1}}^{2} & \sigma_{\mathrm{a}_{1} \mathrm{a}_{2}} \\
\sigma_{\mathrm{a}_{2} \mathrm{a}_{1}} & \sigma_{\mathrm{a}_{2}}^{2}
\end{array}\right]\right),
$$

$$
\begin{gathered}
{\left[\begin{array}{l}
\mathrm{pe}_{1} \\
\mathrm{pe}_{2}
\end{array}\right] \sim N\left(0, \mathbf{I} \otimes\left[\begin{array}{cc}
\sigma_{\mathrm{pe}_{1}}^{2} & 0 \\
0 & \sigma_{\mathrm{pe}_{2}}^{2}
\end{array}\right]\right), \text { and }} \\
{\left[\begin{array}{c}
\mathrm{e}_{1} \\
\mathrm{e}_{2}
\end{array}\right] \sim N\left(0, \mathbf{I} \otimes\left[\begin{array}{cc}
\sigma_{\mathrm{e}_{1}}^{2} & 0 \\
0 & \sigma_{\mathrm{e}_{2}}^{2}
\end{array}\right]\right) .}
\end{gathered}
$$

In the above distributions, $\mathbf{A}$ is the matrix of additive genetic relationships between individuals in the pedigree, $\mathbf{I}$ is the identity matrix, $\sigma_{\mathrm{a}_{i}}^{2}$ is the additive genetic variance of the $i$ th hair cortisol trait value, $\sigma_{\mathrm{a}_{1} \mathrm{a}_{2}}$ is the additive genetic covariance between 2 cortisol traits, $\sigma_{\mathrm{pe}_{i}}^{2}$ is the permanent environmental variance of the $i$ th hair cortisol trait value, and $\sigma_{\mathrm{e}_{i}}^{2}$ is the residual variance of the $i$ th hair cortisol trait value. All the data management steps were carried out in Python (version 3.7, Python, Software Foundation).

\section{RESULTS}

\section{Influence of Nongenetic Factors on 3 Hair Cortisol Traits}

Descriptive statistics of HCC, PC, and HCCP traits are shown in Table 1 . The coefficient of variation for PC was lower (15.11\%) than that for HCC (22.83\%), whereas HCCP had the highest value $(25.41 \%)$. All the phenotypes approximately accorded with a normal distribution by histogram inspection (Supplemental Figure S1, https://doi.org/10.6084/m9.figshare.13543673, Shi, 2021a).

In this study, sample year, sample season, hair color, and year-season interaction had significant $(P<0.05)$ effects on HCC and PC; however, HCCP was not affected by hair color $(P=0.09)$. The effect of parity was not significant. On average, HCC in black hair was lower $(-2.09 \mathrm{ng} / \mathrm{mL})$ than that in white hair (Table 2), and the same was observed for PC $(-0.05 \mathrm{mg} / \mathrm{mL})$ and HCCP (-6.28 ng/mg). Among different seasons, the highest value of HCC was observed in autumn (2.32

Table 1. Descriptive statistics of HCC, PC, and HCCP traits ${ }^{1}$

\begin{tabular}{lcccccc}
\hline Trait & $\mathrm{n}$ & Mean & $\mathrm{SD}$ & $\mathrm{CV}(\%)$ & Minimum & Maximum \\
\hline HCC & 1,086 & 29.35 & 6.70 & 22.83 & 8.49 & 54.06 \\
PC & 1,086 & 0.139 & 0.021 & 15.11 & 0.109 & 0.403 \\
HCCP & 1,086 & 214.45 & 54.49 & 25.41 & 49.33 & 412.73
\end{tabular}

${ }^{1} \mathrm{HCC}=$ hair cortisol concentration $(\mathrm{ng} / \mathrm{mL}) ; \mathrm{HCCP}=$ ratio of $\mathrm{HCC}$ to $\mathrm{PC}(\mathrm{ng} / \mathrm{mg}) ; \mathrm{PC}=$ protein concentration $(\mathrm{mg} / \mathrm{mL})$. 
Table 2. Estimates of fixed effects for 3 hair cortisol traits ${ }^{1}$

\begin{tabular}{llllll}
\hline \multirow{2}{*}{ Effect } & & & \multicolumn{3}{c}{ LSM } \\
\cline { 4 - 6 } & Level & $\mathrm{n}$ & $\mathrm{HCC}$ & $\mathrm{PC}$ & $\mathrm{HCCP}$ \\
\hline \multirow{2}{*}{ Year } & 2014 & 545 & $2.53^{*}$ & $0.008^{*}$ & $4.59^{*}$ \\
& 2015 & 541 & 0 & 0 & 0 \\
Season & Summer & 382 & $2.31^{*}$ & $-0.03^{*}$ & $60.07^{*}$ \\
& Autumn & 349 & $2.32^{*}$ & $-0.02^{*}$ & $44.95^{*}$ \\
\multirow{2}{*}{ Color } & Winter & 355 & 0 & 0 & 0 \\
& Black & 720 & $-2.09^{*}$ & $-0.05^{*}$ & -6.28 \\
& White & 366 & 0 & 0 & 0 \\
\hline
\end{tabular}

${ }^{1} \mathrm{HCC}=$ hair cortisol concentration $(\mathrm{ng} / \mathrm{mL}) ; \mathrm{PC}=$ protein concentration $(\mathrm{mg} / \mathrm{mL}) ; \mathrm{HCCP}=$ ratio of HCC to PC $(\mathrm{ng} / \mathrm{mg})$.

*Significant difference from the last level in each effect $(P<0.05)$.

$\mathrm{ng} / \mathrm{mL}$ ), whereas a numerically lower value (2.31 ng/ $\mathrm{mL}$ ) was obtained in autumn. The HCCP reached a peak $(60.07 \mathrm{ng} / \mathrm{mg})$, and $\mathrm{PC}$ reached its nadir in summer $(-0.03 \mathrm{mg} / \mathrm{mL})$.

\section{Relationship Between Hair Cortisol Traits and Pregnancy Status}

The values of $\mathrm{R}^{2}$ for polynomial functions increased when higher degrees are included in the model, but the least RMSE was observed when function degree equals to 6,7 , and 5 for aHCC1, aPC1, and aHCCP1, respectively (Table 3 ). The average values of 3 phenotypes within 50 DIM_W were noted as blue points in 3 panels of Figure 3, and red polynomial curves were also fitted for each adjusted trait. The patterns of the aHCC1 $\left(\mathrm{R}^{2}=0.45\right)$ and aHCCP1 $\left(\mathrm{R}^{2}=0.44\right)$ curves were comparable, whereas the aPC1 $\left(\mathrm{R}^{2}=0.48\right)$ curve was distinctive in later pregnancy stage. The best curve for aHCC1 and aHCCP1(degree $=6$ and 5 ) indicated a peak value around the fifth to tenth week postpartum and saw a decrease until another obvious peak at the end of pregnancy. However, for the aPC1 curve, it reached its nadir at the 15 th week after reaching a peak at the same week as the other 2 traits and then bounced back, with another peak being observed at about the 49th week. The trajectories of bias and variance changing in different polynomial degrees were shown in Supplemental Figure S2 (https://doi.org/10 .6084/m9.figshare.13543670, Shi, 2021b).

\section{Relationship Between Hair Cortisol Traits and Heat Stress Indicators}

Overall, aHCC2 and aPC2 were correlated with TEM_df positively, whereas they correlated with other 3 indicators negatively; the correlation between aHCCP2 and these heat stress indicators were opposite (Table 4). Moreover, similar correlations (regardless of the signs) were observed within each trait. aHCC2 was the least correlated with these heat stress indicators, with absolute coefficients ranging from 0.09 to 0.21 , whereas aPC2 was the most correlated (absolute values ranging from 0.47 to 0.52 ). The correlation between aHCCP2 and these indicators were relatively weak (from 0.18 to 0.23 ) compare with aPC2. Basically, the days selected for prediction models were diverse when using different indicators or predicting different traits (Table 5). The regression models have better predictions for aPC2, with $\mathrm{R}^{2}$ ranging from 0.35 to 0.38 , and moderate accuracies were obtained when predicting aHCCP2 $\left(\mathrm{R}^{2}=0.09 \sim 0.18\right)$. However, none of the heat stress indicators could be used to predict aHCC2 accurately $\left(\mathrm{R}^{2}=0.03 \sim 0.09\right)$.

Furthermore, average milk yield and THI data before the summer 2015 sampling day were matched to those of the previous $30 \mathrm{~d}$. Pearson correlation test showed that average milk yield and average THI were negatively (from -0.33 to -0.32 ) and positively (from 0.32 to 0.48 ) correlated with adjusted phenotypes, respectively (Table 6).

Table 3. Model fitness ${ }^{1}$ of different polynomial functions for 3 hair cortisol traits ${ }^{2}$

\begin{tabular}{|c|c|c|c|c|c|c|}
\hline \multirow{2}{*}{$\begin{array}{l}\text { Function } \\
\text { degree }\end{array}$} & \multicolumn{3}{|c|}{$\mathrm{R}^{2}$} & \multicolumn{3}{|c|}{ RMSE } \\
\hline & aHCC1 & aPC1 & aHCCP1 & aHCC1 & aPC1 & aHCCP1 \\
\hline 1 & 0.03 & 0.17 & 0.29 & 5.19 & $1.98 \mathrm{E}-02$ & 28.82 \\
\hline 2 & 0.19 & 0.25 & 0.29 & 4.72 & $1.89 \mathrm{E}-02$ & 28.78 \\
\hline 3 & 0.26 & 0.25 & 0.40 & 4.55 & $1.91 \mathrm{E}-02$ & 26.35 \\
\hline 4 & 0.30 & 0.32 & 0.41 & 4.58 & $1.86 \mathrm{E}-02$ & 26.25 \\
\hline 5 & 0.42 & 0.41 & 0.44 & 4.24 & $1.75 \mathrm{E}-02$ & 26.19 \\
\hline 6 & 0.45 & 0.44 & 0.44 & 4.22 & $1.70 \mathrm{E}-02$ & 26.30 \\
\hline 7 & 0.48 & 0.48 & 0.45 & 4.35 & $1.68 \mathrm{E}-02$ & 29.42 \\
\hline 8 & 0.54 & 0.50 & 0.46 & 4.28 & $1.71 \mathrm{E}-02$ & 30.65 \\
\hline
\end{tabular}

${ }^{1} \mathrm{RMSE}=$ the total root mean square error of training and 5-fold cross validation.

${ }^{2} \mathrm{aHCC} 1$ = adjusted hair cortisol concentration for pregnancy stress analysis $(\mathrm{ng} / \mathrm{mL})$; aPC1 = adjusted protein concentration for pregnancy stress analysis $(\mathrm{mg} / \mathrm{mL})$; aHCCP1 = ratio of aHCC1 to aPC1 for pregnancy stress analysis $(\mathrm{ng} / \mathrm{mg})$. 


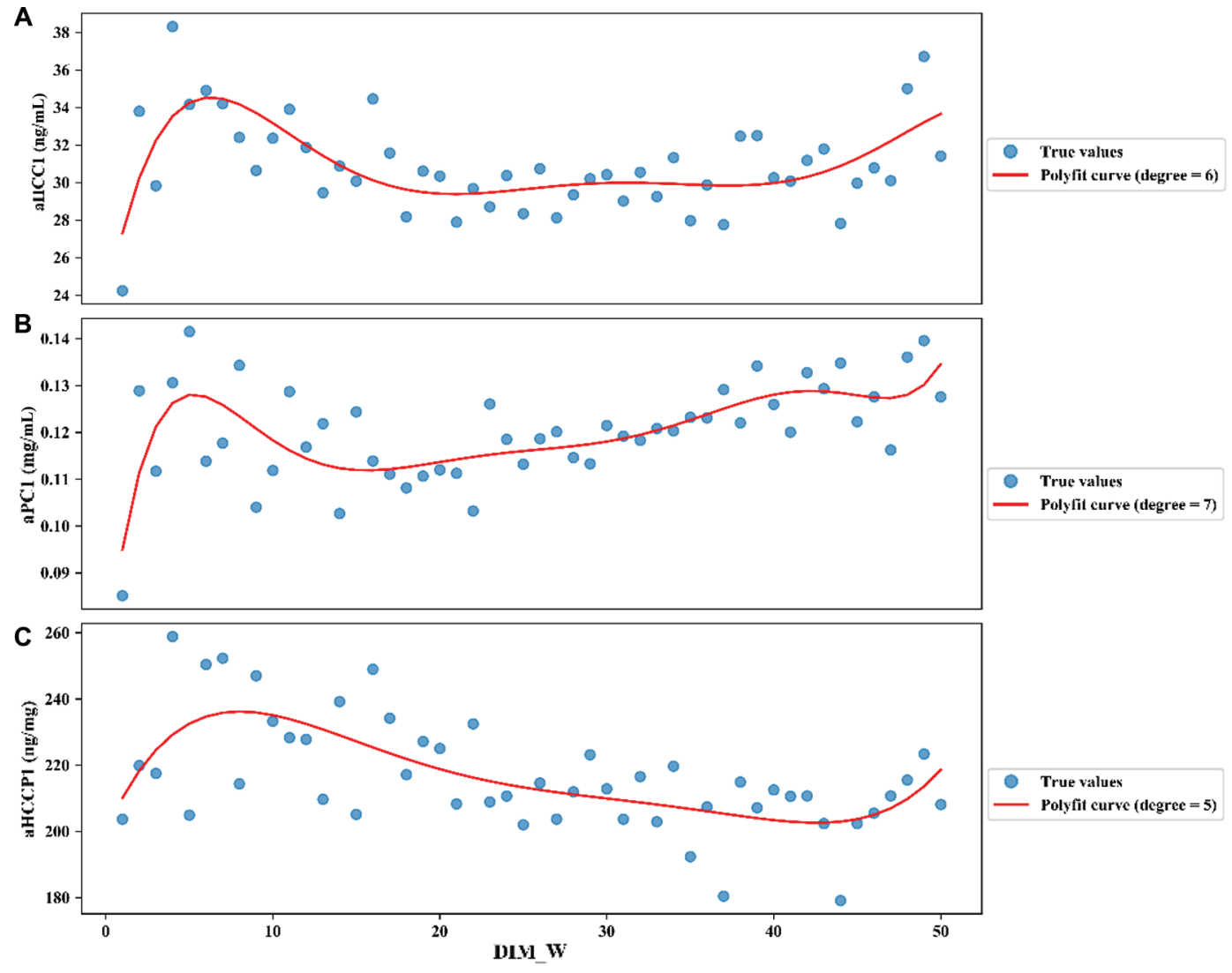

Figure 3. (A) Polynomial fit curves and true values for adjusted hair cortisol concentration for pregnancy stress analysis (aHCC1) from days in milk by week (DIM_W) 1 to 50; (B) polynomial fit curves and true values for adjusted protein concentration for pregnancy stress analysis (aPC1) from DIM_W 1 to 50; (C) polynomial fit curves and true values for ratio of aHCC1 to aPC1 for pregnancy stress analysis (aHCCP1) from DIM_W 1 to 50. Red lines indicate the curve using polynomial functions with degree 6 , 7 , and 5 for aHCC1, aPC1, and aHCCP1, respectively.

\section{Genetic Parameters for Hair Cortisol Traits}

The genetic parameters and variance components estimated using the repeatability model are shown in Table 7. The additive genetic variances of HCC and $\mathrm{PC}$ were higher than corresponding permanent environmental variances (3.61 vs. $0.43 ; 1.52 \mathrm{E}-05$ vs. $2.39 \mathrm{E}-06)$, whereas the results were reversed for HCCP (40.60 vs. 108.51). Most of the standard errors of additive and permanent genetic variances exceeded the corresponding estimates. Generally, 3 hair cortisol traits were all low heritable $\left(\mathrm{h}^{2}<0.10\right)$ and all the standard errors for $\mathrm{h}^{2}$ and $\mathrm{r}$ were as high as the estimates. The $\mathrm{r}$ of HCCP is much higher than corresponding $\mathrm{h}^{2}$ (0.065 vs. 0.018) comparing with HCC and PC.

The genetic and phenotypic correlations among 3 traits are shown in Table 8. Both the genetic and phenotypic correlations between $\mathrm{PC}$ and $\mathrm{HCC}$ were not significant due to high SE; an intermediate coefficient $(0.691 \pm 0.53)$ was obtained for the genetic correlation, and a negligible trend $(0.053 \pm 0.04)$ was observed for the phenotypes between these 2 traits. Additionally, no significant genetic correlation was observed between $\mathrm{PC}$ and $\mathrm{HCCP}$, with a relatively low magnitude estimate and extremely high SE $(0.311 \pm 0.94)$; however, the phenotypes of these 2 traits correlated negatively $(-0.313 \pm 0.04, P<0.05)$. The HCCP and HCC were highly correlated genetically and phenotypically $(0.947$

Table 4. Pearson correlation coefficients between cortisol traits and heat stress indicators ${ }^{1}$

\begin{tabular}{lrrrr}
\hline Variable & THI & THI_M & THI_m & TEM_df \\
\hline aHCC2 & -0.11 & -0.09 & -0.14 & 0.21 \\
aPC2 & -0.49 & -0.47 & -0.50 & 0.52 \\
aHCCP2 & 0.23 & 0.23 & 0.21 & -0.18 \\
\hline
\end{tabular}

${ }^{1}$ All the correlations shown are significant $(P<0.05)$. aHCC2 $=$ adjusted hair cortisol concentration for heat stress analysis $(\mathrm{ng} / \mathrm{mL})$; aPC2 = adjusted protein concentration for heat stress analysis (mg/ $\mathrm{mL}) ; \mathrm{aHCCP} 2=$ ratio of aHCC2 to aPC2 for heat stress analysis (ng/ $\mathrm{mg})$; THI = temperature-humidity index; THI_M = daily maximum temperature-humidity index; THI_m = daily minimum temperaturehumidity index; TEM_df $=$ daily temperature difference $\left({ }^{\circ} \mathrm{C}\right)$. 
Table 5. Covariates selected by forward selection method and the accuracies $^{1}$ of each linear regression model incorporating 4 heat stress indicators

\begin{tabular}{lllc}
\hline Trait $^{2}$ & Indicator $^{3}$ & Selected days & Accuracy \\
\hline aHCC2 & THI & $-31,-17,-16$ & 0.09 \\
& THI_M & $-26,-25$ & 0.03 \\
& THI_m & $-28,-26,-25$ & 0.09 \\
aPC2 & TEM_df & $-22,-5,-1$ & 0.09 \\
& THI & $-25,-24,-12,-2$ & 0.38 \\
& THI_M & $-30,-24,-18$ & 0.35 \\
& THI_m & $-26,-13,-3$ & 0.37 \\
aHCCP2 & TEM_df & $-30,-5,-1$ & 0.35 \\
& THI_ & $-28,-26,-24,-18$ & 0.21 \\
& THI_M & $-9,-7,-4,-2$ & 0.09 \\
& THI_m & $-26,-15,-12$ & 0.18 \\
& TEM_df & $-15,-9,-5$ & 0.20 \\
\hline
\end{tabular}

${ }^{1}$ Accuracies of models were evaluated by the average $\mathrm{R}^{2}$ of 5 -fold cross validation.

${ }^{2}$ aHCC $2=$ adjusted hair cortisol concentration for heat stress analysis $(\mathrm{ng} / \mathrm{mL})$; $\mathrm{aPC} 2=$ adjusted protein concentration for heat stress analysis $(\mathrm{mg} / \mathrm{mL}) ;$ aHCCP $2=$ ratio of $\mathrm{aHCC} 2$ to $\mathrm{aPC} 2$ for heat stress analysis (ng/mg).

${ }^{3} \mathrm{THI}=$ daily average temperature-humidity index; THI_M $=$ daily maximum temperature-humidity index; THI_m = daily minimum temperature-humidity index; TEM_df = daily temperature difference $\left({ }^{\circ} \mathrm{C}\right)$.

${ }^{4}$ The numbers indicate how many days before the sampling day, and the minus sign indicates before; the corresponding indicators of selected days are the covariates of linear regression models.

\pm 0.01 and $0.909 \pm 0.07$, respectively) at significant levels.

The bivariate analysis results for hair cortisol traits are shown in Table 9. The addictive genetic variances remained stable in both groups for HCC (3.18 vs. 4.05 and 13.96 vs. 18.52 , respectively), while nearly 2 - to 4-fold changes in different environments were observed for PC and HCCP. However, higher additive genetic variances were obtained for all traits when evaluated seasonal effect. Overall, the heritabilities for the traits among the paired groups remained equivalent, except for HCCP (0.131 vs. 0.041 and 0.289 vs. 0.460 , respectively). Heritabilities estimated in various seasons were much higher than those in different pregnancy stages.
Table 6. Pearson correlation coefficients of adjusted hair cortisol traits with temperature-humidity index (THI) and average milk production in the summer of $2015^{1}$

\begin{tabular}{lcc}
\hline Trait $^{2}$ & THI & Milk \\
\hline aHCC2 & 0.48 & -0.32 \\
aPC2 & 0.32 & -0.33 \\
aHCCP2 & 0.48 & -0.32
\end{tabular}

${ }^{1}$ The average THI and milk production of $30 \mathrm{~d}$ before the sampling day were evaluated.

${ }^{2}$ aHCC2 $=$ adjusted hair cortisol concentration for heat stress analysis $(\mathrm{ng} / \mathrm{mL}) ; \mathrm{aPC} 2=$ adjusted protein concentration for heat stress analysis $(\mathrm{mg} / \mathrm{mL})$; aHCCP2 $=$ ratio of aHCC2 to aPC2 for heat stress analysis $(\mathrm{ng} / \mathrm{mg})$.

The HCC produced comparable $\mathrm{h}^{2}(0.080$ and 0.104 , respectively) with high SE (0.15 and 0.06, respectively) for the stress and nonstress pregnancy stages. However, the SE was approximately half of the corresponding estimates for season groups $(0.347 \pm 0.14$ and $0.390 \pm$ 0.15 , respectively). For PC, the SE was relatively small comparing with the $\mathrm{h}^{2}$ in both pregnancy and season groups, and the relationship of SE and $\mathrm{h}^{2}$ for HCCP was similar with that of HCC. Negative correlations were detected in all groups of paired environments, excluding PC in the pregnancy group (0.134). However, only the season group of $\mathrm{PC}$ reached a significance $(P$ $=0.041$ ) level, because the SE of other correlation coefficients were high (ranged from 0.27 to 0.91 ). The $\mathrm{r}_{\mathrm{g}}$ of all traits between seasons were moderate and negative (from -0.385 to -0.113 ).

\section{DISCUSSION}

We determined the average HCC as $29.35 \mathrm{ng} / \mathrm{mL}$ (Table 1) in $3 \mathrm{~mL}$ of methane added to $150 \mathrm{mg}$ of hair for extraction; therefore, the scale could be converted to $587 \mathrm{pg} / \mathrm{mg}$ in this study, which was higher than the range reported by previous studies $(0.25-50 \mathrm{pg} / \mathrm{mg}$; González-De-La-Vara et al., 2011; Montillo et al., 2014; Ghassemi Nejad et al., 2014). There is still much work

Table 7. Estimates of genetic parameters of hair cortisol concentration traits (SE in parentheses) ${ }^{1}$

\begin{tabular}{lccccc}
\hline Trait $^{2}$ & $\sigma_{a}^{2}$ & $\sigma_{p e}^{2}$ & $\sigma_{e}^{2}$ & $\mathrm{~h}^{2}$ & $\mathrm{r}$ \\
\hline HCC & 3.61 & 0.43 & 40.40 & 0.082 & 0.092 \\
& $(3.12)$ & $(3.16)$ & $(2.42)$ & $(0.07)$ & $(0.07)$ \\
PC & $1.52 \mathrm{E}-05$ & $2.30 \mathrm{E}-06$ & $2.78 \mathrm{E}-04$ & 0.051 & 0.059 \\
& $(1.45 \mathrm{E}-05)$ & $(1.72 \mathrm{E}-05)$ & $(1.69 \mathrm{E}-05)$ & $(0.05)$ & $(0.06)$ \\
HCCP & 40.60 & 108.51 & $2,157.38$ & 0.018 & 0.065 \\
& $(114.77)$ & $(140.01)$ & $(130.12)$ & $(0.05)$ & $(0.06)$ \\
\hline
\end{tabular}

${ }^{1} \sigma_{a}^{2}=$ additive genetic variance; $\sigma_{p e}^{2}=$ permanent environmental variance; $\sigma_{e}^{2}=$ residual variance.

${ }^{2} \mathrm{HCC}=$ hair cortisol concentration $(\mathrm{ng} / \mathrm{mL}) ; \mathrm{PC}=$ protein concentration $(\mathrm{mg} / \mathrm{mL})$; HCCP $=$ ratio of $\mathrm{HCC}$ to $\mathrm{PC}(\mathrm{ng} / \mathrm{mg})$. 
Table 8. Genetic and phenotypic correlations (SE in parentheses) among hair cortisol traits ${ }^{1}$

\begin{tabular}{lllr}
\hline Trait $^{2}$ & \multicolumn{1}{c}{ HCC } & \multicolumn{1}{c}{ PC } & \multicolumn{1}{c}{ HCCP } \\
\hline HCC & 1 & $0.053(0.04)$ & $0.909^{*}(0.01)$ \\
PC & $0.691(0.53)$ & 1 & $-0.313^{*}(0.04)$ \\
HCCP & $0.947^{*}(0.07)$ & $0.311(0.94)$ & 1 \\
\hline
\end{tabular}

${ }^{1}$ Genetic correlations are shown below diagonal; phenotypic correlations are shown above diagonal.

${ }^{2} \mathrm{HCC}=$ hair cortisol concentration $(\mathrm{ng} / \mathrm{mL}) ; \mathrm{PC}=$ protein concentration $(\mathrm{mg} / \mathrm{mL}) ; \mathrm{HCCP}=$ ratio of $\mathrm{HCC}$ to $\mathrm{PC}(\mathrm{ng} / \mathrm{mg})$.

*Significant correlation $(P<0.05)$.

to do to establish the normal ranges of cortisol in hair, as it may be affected by a variety of factors, such as species and processing methods (Burnard et al., 2017). The main procedures used in previous studies included evaporation of methanol and sample reconstitution before determination, whereas we determined the cortisol concentration using unevaporated methanol. This suggests that the extraction process would have a large effect on the HCC value. However, in the current study, we still generated similar findings and several meaningful results with a different scale of HCC.

\section{Factors Affecting the Hair Cortisol Concentration}

In this study, the $\mathrm{HCC}$ in white hair was significantly higher than that in black hair (Table 2), which was consistent with the results of previous studies (González-De-La-Vara et al., 2011; Burnett et al., 2014). González-De-La-Vara et al. (2011) found that the HCC in 2-yr-old cows was significantly higher in white hair than in black hair (23.84 and $14.31 \mathrm{pg} / \mathrm{mg}$, respectively), and the results reported by Burnett et al. (2014) also indicated a greater concentration of cortisol in white hair (7.8 and $3.8 \mathrm{pg} / \mathrm{mg}$, respectively). In addition, a recent study (Ghassemi Nejad et al., 2017) illustrated the same pattern of hair color and cortisol concentration (14.5 pg/mg for white hair and $13.7 \mathrm{pg} /$ $\mathrm{mg}$ for black hair, respectively). We also found that the cortisol traits varied significantly among years, which might have been caused by intra-assay variation.

The current study provided the first measurement of PC in hair, and we found that hair color also plays an important role in PC, which was significantly higher in white hair than in black hair. As stated in the introduction, higher melanin pigment concentrations might contribute to a higher PC in the hair shaft; however, the

Table 9. Genetic parameters for hair cortisol traits in different paired environments (SE in parentheses) ${ }^{1}$

\begin{tabular}{|c|c|c|c|c|c|c|}
\hline Trait $^{2}$ & Effect & Group & $\sigma_{a}^{2}$ & $\sigma_{e}^{2}$ & $h^{2}$ & $\mathrm{r}_{\mathrm{g}}$ \\
\hline \multirow[t]{4}{*}{$\mathrm{HCC}$} & \multirow[t]{2}{*}{ Pregnancy } & Stress & $\begin{array}{c}3.18 \\
(6.17)\end{array}$ & $\begin{array}{c}36.64 \\
(7.31)\end{array}$ & $\begin{array}{c}0.080 \\
(0.15)\end{array}$ & -0.608 \\
\hline & & Nonstress & $\begin{array}{c}4.05 \\
(2.65)\end{array}$ & $\begin{array}{l}34.80 \\
(3.64)\end{array}$ & $\begin{array}{c}0.104 \\
(0.06)\end{array}$ & $(0.91)$ \\
\hline & \multirow[t]{2}{*}{ Season } & Winter & $\begin{array}{l}13.96 \\
(6.60)\end{array}$ & $\begin{array}{l}26.26 \\
(5.72)\end{array}$ & $\begin{array}{c}0.347 \\
(0.14)\end{array}$ & -0.113 \\
\hline & & Summer & $\begin{array}{l}18.52 \\
(8.73)\end{array}$ & $\begin{array}{c}28.91 \\
(6.82)\end{array}$ & $\begin{array}{c}0.390 \\
(0.15)\end{array}$ & $(0.27)$ \\
\hline \multirow[t]{4}{*}{$\mathrm{PC}$} & \multirow[t]{2}{*}{ Pregnancy } & Stress & $\begin{array}{c}4.85 \mathrm{E}-05 \\
(2.57 \mathrm{E}-05)\end{array}$ & $\begin{array}{c}2.12 \mathrm{E}-04 \\
(2.51 \mathrm{E}-05)\end{array}$ & $\begin{array}{c}0.186 \\
(0.09)\end{array}$ & 0.134 \\
\hline & & Nonstress & $\begin{array}{c}2.82 \mathrm{E}-05 \\
(1.65 \mathrm{E}-05)\end{array}$ & $\begin{array}{c}1.54 \mathrm{E}-04 \\
(1.83 \mathrm{E}-05)\end{array}$ & $\begin{array}{l}0.155 \\
(0.09)\end{array}$ & $(0.39)$ \\
\hline & \multirow[t]{2}{*}{ Season } & Winter & $\begin{array}{c}1.49 \mathrm{E}-04 \\
(7.02 \mathrm{E}-05)\end{array}$ & $\begin{array}{c}2.22 \mathrm{E}-04 \\
(5.41 \mathrm{E}-05)\end{array}$ & $\begin{array}{c}0.402 \\
(0.16)\end{array}$ & -0.385 \\
\hline & & Summer & $\begin{array}{c}8.66 \mathrm{E}-05 \\
(2.70 \mathrm{E}-05)\end{array}$ & $\begin{array}{c}8.85 \mathrm{E}-05 \\
(1.86 \mathrm{E}-05)\end{array}$ & $\begin{array}{c}0.495 \\
(0.11)\end{array}$ & $(0.22)^{*}$ \\
\hline \multirow[t]{4}{*}{$\mathrm{HCCP}$} & \multirow[t]{2}{*}{ Pregnancy } & Stress & $\begin{array}{c}346.83 \\
(242.14)\end{array}$ & $\begin{array}{r}2,297.60 \\
(261.54)\end{array}$ & $\begin{array}{l}0.131 \\
(0.09)\end{array}$ & -0.906 \\
\hline & & Nonstress & $\begin{array}{c}86.49 \\
(128.77)\end{array}$ & $\begin{array}{r}2,019.01 \\
(210.76)\end{array}$ & $\begin{array}{l}0.041 \\
(0.06)\end{array}$ & $(0.59)$ \\
\hline & \multirow[t]{2}{*}{ Season } & Winter & $\begin{array}{c}449.98 \\
(250.10)\end{array}$ & $\begin{array}{r}1,108.25 \\
(234.29)\end{array}$ & $\begin{array}{c}0.289 \\
(0.14)\end{array}$ & -0.148 \\
\hline & & Summer & $\begin{array}{r}1,547.58 \\
(604.02)\end{array}$ & $\begin{array}{r}1,817.59 \\
(426.98)\end{array}$ & $\begin{array}{c}0.460 \\
(0.14)\end{array}$ & $(0.27)$ \\
\hline
\end{tabular}

${ }^{1} \sigma_{a}^{2}=$ additive genetic variance; $\sigma_{e}^{2}=$ residual variance; $\mathrm{r}_{\mathrm{g}}=$ genetic correlation between paired environment groups.

${ }^{2} \mathrm{HCC}=$ hair cortisol concentration $(\mathrm{ng} / \mathrm{mL}) ; \mathrm{PC}=$ protein concentration $(\mathrm{mg} / \mathrm{mL}) ; \mathrm{HCCP}=$ ratio of $\mathrm{HCC}$ to $\mathrm{PC}(\mathrm{ng} / \mathrm{mg})$.

*Significant correlation $(P<0.05)$. 
opposite outcome was obtained. The total PC in the hair shaft may increase in the absence of pigmentation, and more research is necessary to reveal the underlying mechanism of the PC in hair. We found that hair color was no longer a relevant factor concern $(P=0.09)$ after using $\mathrm{HCCP}$ (HCC divided by $\mathrm{PC}$ ) as an indicator, which indicated that a potential correlation existed between hair color and PC. Additionally, HCCP could be used to capture the variation of HPA response to stress in cattle regardless of the hair color.

\section{Connection of Hair Cortisol Traits and Pregnancy Stress}

As an indicator of chronic stress, hair cortisol can reflect the average stress level of a period before sampling, and many criteria have been suggested to accurately evaluate hair analysis results (Wennig, 2000; Burnett et al., 2014). We produced curves (Figure 3) indicating how the adjusted hair cortisol traits changed during pregnancy, in which DIM was calculated from the sample day and calving day. Reasonable curves were generated using polynomial functions based on the balance of model bias and variance. A relatively delayed peak, which explained calving stress, appeared at the 5th to 10th DIM week for all dependent variables. This peak was also demonstrated by a previous study (Burnett et al., 2015), which found that the HCC was the highest at 3 wk after calving. Furthermore, all adjusted phenotypes increased in the last 5 wk of pregnancy. This agreed with previous results (Kirschbaum et al., 2009; Fairbanks et al., 2011), which explained that in the third trimester of pregnancy, women entered a phase of mild hypercortisolemia, and the HPA axis would be deactivated to a normal level within a few days after giving birth. We could observe the process of HPA axis activation and deactivation, which indicated that mammals have the same cortisol synthesis mechanism, and hair cortisol traits could be used as an indicator to monitor the reproductive status of cows.

\section{Connection Between Hair Cortisol Traits and Heat Stress}

Few studies have investigated the changing pattern of hair cortisol traits in different seasons or temperatures. Comin et al. (2011) included rearing environment (housing or grazing) and season effects, but the effects of a variety of factors such as diet, social changing group, and transport were confounded. Uetake et al. (2017) compared seasonal changes in HCC in 2 different regions (warm and cold) in Japan and found that cortisol reached a peak in June for both regions. Dairy cows will suffer heat stress when the THI is greater than 68 (Zimbelman et al., 2011), and more cortisol will be produced via the HPA axis as the animals experience chronic stress. The curve of THI changes in Beijing (Figure 1) during experiment years indicated that the THI of summers (August in this study) is higher than 68. The THI of autumns (November in this study) is around 50, whereas the THI of winters (January in this study) is below 40. Our results (Table 2) showed that HCC was relatively high in autumn and summer, where the THI reached its highest level. Additionally, we found that the HCCP was significantly higher in summer than in autumn. Table 5 showed a moderate power of prediction for aPC2 and aHCCP2 using the heat stress indicators. However, we failed to predict aHCC2 using the same method. Most of the days selected for the corresponding prediction models were evenly distributed, i.e., hair cortisol traits may be affected even when animals experienced heat stress $30 \mathrm{~d}$ before the sampling day. However, the 30-d heat stress indicators were consistent in the same sampling season (we sampled on one day for all seasons); therefore, the accuracies of predictions would be compromised. To further reveal the relationship of hair cortisol and heat changes, continuous sampling days are required. Nevertheless, these results suggested that aPC2 and aHCCP2 might provide higher power to test heat stress.

The moderately positive relationship between adjusted hair cortisol traits and THI partially proved the potential value of these traits to substantiate heat stress conditions (Table 6). We assumed higher milk production would cause an increase of hair cortisol because of higher energy expenditure. However, negative correlations were observed for milk production and adjusted phenotypes in this study. As we know, heat stress would cause considerably milk loss in dairy cattle (McDowell et al., 1976), and cows in our study were experiencing continuous heat stress 2 mo before the sampling (Figure 1). Thus, the negative effect of heat on milk yield may be strong enough to compromise the effect of milk yield on hair cortisol traits.

\section{Genetic Merits of Hair Cortisol Traits}

To the best of our knowledge, this study provides the first insight into the genetic variance of hair cortisol traits in ruminants under different environments. The general $\mathrm{h}^{2}$ estimated in the current research were all less than 0.10, which was not consistent with the reported $\mathrm{h}^{2}$ of hair cortisol (ranged from 0.31 to 0.72 ) in primates and human (Fairbanks et al., 2011; Rietschel et al., 2017; Tucker-Drob et al., 2017). However, pedigree structures in these publications were relatively simple. The monkeys were mostly full and half siblings with only 44 parents, and half of cohort in the hu- 
man studies were twins or trizygotic triplets. The cows we used are randomly selected, so the construction of relationship matrix would be sparser than those in the literature. This might be the reason why higher $\mathrm{h}^{2}$ were detected in previous studies. In other studies, where genetic merits of cortisol in other matrices were evaluated, Kadarmideen and Janss (2007) reported a reliable heritability of $0.40(\mathrm{SE}=0.02)$ for urine cortisol in pigs; You et al. (2008) and Pant et al. (2016) found that the cortisol responsiveness of ovine was heritable $\left(\mathrm{h}^{2}=0.28\right)$ by determining the cortisol concentration in serum. These findings reinforced the idea that cortisol trait is highly heritable. Comparing with hair cortisol, the cortisol in urine and serum could monitor acute response of HPA axis by evaluating the concentration a few hours later, but it is not practicable for evaluating chronic stress. Except for the diverse relationship among the cattle in present study, lower $\mathrm{h}^{2}$ and high SE may also have resulted from the complex distribution of phenotypes in different seasons, DIM, and parities, because HCC could be affected by various environmental factors. The variation in biological rhythm, diet, activity, and sample collection procedures (Kudielka et al., 2009), even social and emotion changes (Zhang et al., 2017), are also factors that affect the estimation of genetic components. Thus, a more detailed model was required, and the number of phenotypes used to estimate general genetic parameters was insufficient, such that we observed genetic parameters with relatively high SE values. Additionally, the variation in different testing assays might also have obstructed the accurate estimation of genetic parameters. To obtain accurate estimates in the future, detailed sampling procedures should be implemented to reduce confounding factors (e.g., sampling cows in a specific lactation stage), which is essential to simplify genetic analysis models. Additionally, relationship matrix could be enhanced by combing genotype information from individuals (Misztal et al., 2009; Christensen and Lund, 2010).

The estimated genetic correlations might also have been affected by various factors, including the small data size; however, relatively high coefficients were obtained, which indicated possible genetic relationship among the 3 traits. The phenotypically negative correlation between $\mathrm{PC}$ and $\mathrm{HCCP}$, and the high correlation between $\mathrm{HCC}$ and $\mathrm{HCCP}$, conform to the equation used to calculate HCCP. The results also indicated that HCC was not correlated with PC phenotypically, and this might also be related to various factors that affect both HCC and PC, such as hair color and season, which were demonstrated in previous ANOVA results of this article. A more fixed environment and larger sample size are required to further determine the relationship between protein and cortisol in hair.
The most relevant paper published on the $\mathrm{h}^{2}$ of hair cortisol under different environments was performed using vervet monkeys, where the HCC was measured in higher and lower stress environments (Fairbanks et al., 2011) with stable estimated values $(0.310 \pm 0.13$ and $0.310 \pm 0.14$, respectively). The monkeys were consistent in both environments, which is difficult to imitate in a cattle study. The current study tried to fix the environment without extra factors, then obtained constant and more reliable $h^{2}$ in each environment of season groups. This result proved the assumption that complex environmental factors had adverse effects on $\mathrm{h}^{2}$ estimation, because the model of each environment is less complicated than the general repeatability model. The studies of 299 pigs and 242 sheep also generated lower SE by including simple fixed effects (e.g., sex and birth year) in the model (Kadarmideen and Janss, 2007; Pant et al., 2016). Additionally, the pregnancy group was divided based on DIM_W, where the phenotypes could have higher variation within each circumstance. Consequently, the estimates of $\mathrm{h}^{2}$ in pregnancy groups are less reliable than those in season groups. Therefore, the cortisol response of chronic stress is moderately heritable when the animals in specific seasons are evaluated. The estimates were constantly higher in summer compared with winter, which reinforce the assumption that HPA responds genetically in heat stress conditions. Some cows may be heat resistant, of which the HPA activity stays in a low level, but other cows may be easily disturbed by heat, whose HPA will generate more cortisol. Thus, relatively high genetic variation was captured and higher heritabilities were obtained in summer. In addition, the high $\mathrm{h}^{2}$ in the current study was also consistent with the genetic results of the cortisol awakening response (Wüst et al., 2000; Ouellet-Morin et al., 2009). The cortisol concentration of participants displayed more pronounced genetic effects during laboratory test days, which may be resulted from an HPA axis response to the unfamiliar environment and tasks (Franz et al., 2010). This also suggested that hair cortisol traits could be used to measure long-term HPA activity, which could provide an integrated genetic method to analyze stress response pathways.

For the $\mathrm{G} \times \mathrm{E}$ analysis, Fairbanks et al. (2011) detected a significantly high correlation $(0.790 \pm 0.33)$ of HCC between 2 environments, although no significant correlation existed in the current study for 2 paired groups $(-0.608 \pm 0.91,-0.113 \pm 0.27)$. However, we did find that PC was significantly correlated $(-0.385$ \pm 0.22 ) between different seasons. The correlation coefficients in the current study may not have been estimated accurately because of the small sample size and less overlapping pedigree information. However, the 
results indicated a high degree of genotype by environment interaction for cortisol traits in each paired group, as indicated by the low or negative coefficient, which suggested that stressful status could interact with genetic vulnerability to produce depression or biological disorders (Suomi, 2006). Instability of HCC between 2 years (0.32) was also detected in twins (Rietschel et al., 2017), and a relatively high correlation was found in the same year (0.42 to 0.66 ).

\section{CONCLUSIONS}

The present study demonstrated that HCC and PC are significantly associated with hair color, seasonal effect, and pregnancy status, whereas HCCP is not influenced by hair color. Therefore, HCCP has potential as an indicator of HPA response to stressors without considering the effect of hair color. After adjusting confounding factors, the best-fitting curves indicated that HCC, PC, and HCCP had similar and moderate relationships with pregnancy status, thus could be used as reliable indicators to substantiate chronic HPA response to pregnancy stress. Although predicting cortisol levels using heat stress indicators is not accurate enough, we do find moderately positive relationship between hair cortisol traits and THI, which indicated the potential value of hair cortisol to measure chronic heat stress. Detailed analysis and more data are necessary to produce reliable estimations of general heritabilities and correlations, but most of the $h^{2}$ was relatively high and accurate when animals in the same effect group (especially season) were evaluated, indicating the genetic mechanisms of HPA response could be measured using these traits. We failed to detect the genetical difference of hair cortisol traits under varied circumstances, but a certain magnitude of $\mathrm{G} \times \mathrm{E}$, which was indicated by low or negative coefficient, was observed. Collectively, this research validates the factors that effects hair cortisol and protein level in cattle and indicates the potential association between them. Furthermore, the results reveal how hair cortisol traits are related to chronic stress, to an extent, and provides the first insight into the genetic background of hair cortisol traits in ruminants.

\section{ACKNOWLEDGMENTS}

This work was supported by China Agriculture Research System (CARS-36), National Agricultural Genetic Improvement Program (2130135), Beijing Sanyuan Breeding Technology Ltd Co. funded project (SYZYZ20190005), the Program for Changjiang Scholar and Innovation Research Team in University (IRT_15R62), and China Scholarship Council (No.
201913043). We thank Qin Chu for reviewing the manuscript and providing critical revision suggestions, and Ganghui Dong, Xinyi Yan, Zezhao Wang, ZhiChao Zhang, Hetian Huang, Xiang Li, Qinglei Xu, Wei Xu, Jiangang Qi (China Agricultural University), along with other CAU cattle genetics and breeding research team members who participated in sample collection and provided helpful hints in discussion. All of the authors declare that they have no competing interests.

\section{REFERENCES}

Akaike, H. 1975. A new look at the statistical model identification. IEEE Trans. Automat. Contr. 19:716-723. https://doi.org/10 .1109/TAC.1974.1100705.

Aoki Cerri, R. L., A. M. Tabmasbi, and D. M. Veira. 2012. Hair cortisol concentrations-influence of colour and locations in Holstein cows. J. Dairy Sci. 95:S574.

Bautista, L. E., P. K. Bajwa, M. M. Shafer, K. M. C. Malecki, C. A. McWilliams, and A. Palloni. 2019. The relationship between chronic stress, hair cortisol and hypertension. Int. J. Cardiol. Hypertens. 2:100012. https://doi.org/10.1016/j.ijchy.2019.100012.

Burnard, C., C. Ralph, P. Hynd, J. Hocking Edwards, and A. Tilbrook. 2017. Hair cortisol and its potential value as a physiological measure of stress response in human and non-human animals. Anim. Prod. Sci. 57:401-411. https://doi.org/10.1071/AN15622.

Burnett, T. A., A. M. L. Madureira, B. F. Silper, A. Nadalin, A. Tahmasbi, D. M. Veira, and R. L. A. Cerri. 2014. Short communication: Factors affecting hair cortisol concentrations in lactating dairy cows. J. Dairy Sci. 97:7685-7690. https://doi.org/10.3168/ jds.2014-8444.

Burnett, T. A., A. M. L. Madureira, B. F. Silper, A. Tahmasbi, A. Nadalin, D. M. Veira, and R. L. A. Cerri. 2015. Relationship of concentrations of cortisol in hair with health, biomarkers in blood, and reproductive status in dairy cows. J. Dairy Sci. 98:4414-4426. https://doi.org/10.3168/jds.2014-8871.

Christensen, O. F., and M. S. Lund. 2010. Genomic prediction when some animals are not genotyped. Genet. Sel. Evol. 42:2. https:// doi.org/10.1186/1297-9686-42-2.

Chrousos, G. P. 2009. Stress and disorders of the stress system. Nat. Rev. Endocrinol. 5:374-381. https://doi.org/10.1038/nrendo.2009 .106 .

Comin, A., T. Peric, M. Corazzin, M. C. Veronesi, T. Meloni, V. Zufferli, G. Cornacchia, and A. Prandi. 2013. Hair cortisol as a marker of hypothalamic-pituitary-adrenal axis activation in Friesian dairy cows clinically or physiologically compromised. Livest. Sci. 152:36-41. https://doi.org/10.1016/j.livsci.2012.11.021.

Comin, A., A. Prandi, T. Peric, M. Corazzin, S. Dovier, and S. Bovolenta. 2011. Hair cortisol levels in dairy cows from winter housing to summer highland grazing. Livest. Sci. 138:69-73. https://doi.org/ 10.1016/j.livsci.2010.12.009.

Davenport, M. D., S. Tiefenbacher, C. K. Lutz, M. A. Novak, and J. S. Meyer. 2006. Analysis of endogenous cortisol concentrations in the hair of rhesus macaques. Gen. Comp. Endocrinol. 147:255-261. https://doi.org/10.1016/j.ygcen.2006.01.005.

Fairbanks, L. A., M. J. Jorgensen, J. N. Bailey, S. E. Breidenthal, R. Grzywa, and M. L. Laudenslager. 2011. Heritability and genetic correlation of hair cortisol in vervet monkeys in low and higher stress environments. Psychoneuroendocrinology 36:1201-1208. https://doi.org/10.1016/j.psyneuen.2011.02.013.

Falconer, D. S., and T. F. C. Mackay. 1996. Introduction to Quantitative Genetics. 4th ed. Longman Group.

Forslund, K.B., Ö.A. Ljungvall, and B.V. Jones. 2010. Low cortisol levels in blood from dairy cows with ketosis: A field study. Acta Vet. Scand. 52:31.

Franz, C. E., T. P. York, L. J. Eaves, S. P. Mendoza, R. L. Hauger, D. H. Hellhammer, K. C. Jacobson, S. Levine, S. J. Lupien, M. 
J. Lyons, E. Prom-Wormley, H. Xian, and W. S. Kremen. 2010. Genetic and environmental influences on cortisol regulation across days and contexts in middle-aged men. Behav. Genet. 40:467-479. https://doi.org/10.1007/s10519-010-9352-2.

Freedman, L. S., D. Pee, and D. N. Midthune. 1992. The problem of underestimating the residual error variance in forward stepwise regression. Statistician 41:405-412. https://doi.org/10.2307/ 2349005.

Ghassemi Nejad, J., B.-W. Kim, B.-H. Lee, and K.-I. Sung. 2017. Coat and hair color: Hair cortisol and serotonin levels in lactating Holstein cows under heat stress conditions. Anim. Sci. J. 88:190-194. https://doi.org/10.1111/asj.12662.

Ghassemi Nejad, J., J. D. Lohakare, J. K. Son, E. G. Kwon, J. W. West, and K. I. Sung. 2014. Wool cortisol is a better indicator of stress than blood cortisol in ewes exposed to heat stress and water restriction. Animal 8:128-132. https://doi.org/10.1017/ S1751731113001870.

González-de-la-Vara, M. R., R. A. Valdez, V. Lemus-Ramirez, J. C. Vázquez-Chagoyán, A. Villa-Godoy, and M. C. Romano. 2011. Effects of adrenocorticotropic hormone challenge and age on hair cortisol concentrations in dairy cattle. Can. J. Vet. Res. 75:216-221.

Herbut, P., and S. Angrecka. 2012. Forming of temperature-humidity index (THI) and milk production of cows in the free-stall barn during the period of summer heat. Anim. Sci. Pap. Rep. 30:363-372.

Huzzey, J. M., D. V. Nydam, R. J. Grant, and T. R. Overton. 2011. Associations of prepartum plasma cortisol, haptoglobin, fecal cortisol metabolites, and nonesterified fatty acids with postpartum health status in Holstein dairy cows. J. Dairy Sci. 94:5878-5889. https://doi.org/10.3168/jds.2010-3391.

Ismael, A., E. Strandberg, B. Berglund, M. Kargo, A. Fogh, and P. Løvendahl. 2016. Genotype by environment interaction for activity-based estrus traits in relation to production level for Danish Holstein. J. Dairy Sci. 99:9834-9844. https://doi.org/10.3168/jds .2016-11446.

Kadarmideen, H. N., and L. L. G. Janss. 2007. Population and systems genetics analyses of cortisol in pigs divergently selected for stress. Physiol. Genomics 29:57-65. https://doi.org/10.1152/ physiolgenomics.00144.2006.

Kirschbaum, C., A. Tietze, N. Skoluda, and L. Dettenborn. 2009. Hair as a retrospective calendar of cortisol production-Increased cortisol incorporation into hair in the third trimester of pregnancy. Psychoneuroendocrinology 34:32-37. https://doi.org/10.1016/j .psyneuen.2008.08.024.

Kudielka, B. M., D. H. Hellhammer, and S. Dhwust. 2009. Why do we respond so differently? Reviewing determinants of human salivary cortisol responses to challenge. Psychoneuroendocrinology 34:2-18. https://doi.org/10.1016/j.psyneuen.2008.10.004.

Lambertz, C., C. Sanker, and M. Gauly. 2014. Climatic effects on milk production traits and somatic cell score in lactating Holstein-Friesian cows in different housing systems. J. Dairy Sci. 97:319-329. https://doi.org/10.3168/jds.2013-7217.

Lever, J., M. Krzywinski, and N. Altman. 2016. Model selection and overfitting. Nat. Methods 13:703-704. https://doi.org/10.1038/ nmeth.3968.

Madsen, P., and J. Jensen. 2012. A User's Guide to DMU, Version 6, release 5.1. Aarhus University.

Matteri, R. L., J. A. Carroll, and C. J. Dyer. 2000. Neuroendocrine responses to stress. Pages 43-76 in The Biology of Animal Stress. G. P. Moberg and J. A. Mench, ed. CABI Publishing.

McDowell, R. E., N. W. Hooven, and J. K. Camoens. 1976. Effect of climate on performance of holsteins in first lactation. J. Dairy Sci. 59:965-971. https://doi.org/10.3168/jds.S0022-0302(76)84305-6.

Meyer, J. S., and M. A. Novak. 2012. Minireview: Hair cortisol: A novel biomarker of hypothalamic-pituitary-adrenocortical activity. Endocrinology 153:4120-4127. https://doi.org/10.1210/en.2012 $-1226$.

Misztal, I., A. Legarra, and I. Aguilar. 2009. Computing procedures for genetic evaluation including phenotypic, full pedigree, and genomic information. J. Dairy Sci. 92:4648-4655. https://doi.org/10 $.3168 /$ jds.2009-2064.
Montillo, M., A. Comin, M. Corazzin, T. Peric, M. Faustini, M. C. Veronesi, S. Valentini, M. Bustaffa, and A. Prandi. 2014. The effect of temperature, rainfall, and light conditions on hair cortisol concentrations in newborn foals. J. Equine Vet. Sci. 34:774-778. https://doi.org/10.1016/j.jevs.2014.01.011.

Möstl, E., J. L. Maggs, G. Schrötter, U. Besenfelder, and R. Palme. 2002. Measurement of cortisol metabolites in faeces of ruminants. Vet. Res. Commun. 26:127-139. https://doi.org/10.1023/A: 1014095618125

Moya, D., K. S. Schwartzkopf-Genswein, and D. M. Veira. 2013. Standardization of a non-invasive methodology to measure cortisol in hair of beef cattle. Livest. Sci. 158:138-144. https://doi.org/10 .1016/j.livsci.2013.10.007.

Ouellet-Morin, I., G. Dionne, D. Pérusse, S. J. Lupien, L. Arseneault, R. G. Barr, R. E. Tremblay, and M. Boivin. 2009. Daytime cortisol secretion in 6-month-old twins: Genetic and environmental contributions as a function of early familial adversity. Biol. Psychiatry 65:409-416. https://doi.org/10.1016/j.biopsych.2008.10.003.

Pant, S. D., Q. You, L. C. Schenkel, G. V. Voort, F. S. Schenkel, J. Wilton, L. Cain, and N. A. Karrow. 2016. A genome-wide association study to identify chromosomal regions influencing ovine cortisol response. Livest. Sci. 187:40-47. https://doi.org/10.1016/ j.livsci.2016.02.006.

Pragst, F., and M. A. Balikova. 2006. State of the art in hair analysis for detection of drug and alcohol abuse. Clin. Chim. Acta 370:1749. https://doi.org/10.1016/j.cca.2006.02.019.

Ralph, C. R., and A. J. Tilbrook. 2016. Invited review: The usefulness of measuring glucocorticoids for assessing animal welfare. J. Anim. Sci. 94:457-470. https://doi.org/10.2527/jas.2015-9645.

Ravagnolo, O., I. Misztal, and G. Hoogenboom. 2000. Genetic component of heat stress in dairy cattle, development of heat index function. J. Dairy Sci. 83:2120-2125. https://doi.org/10.3168/jds .S0022-0302(00)75094-6.

Rietschel, L., F. Streit, G. Zhu, K. McAloney, J. Frank, B. CouvyDuchesne, S. H. Witt, and T. M. Binz. CortisolNetwork, Major Depressive Disorder Working Group of the Psychiatric Genomics Consortium, J. Mcgrath, I. B. Hickie, N. K. Hansell, M. J. Wright, N. A. Gillespie, A. J. Forstner, T. G. Schulze, S. Wüst, M. M. Nöthen, M. R. Baumgartner, B. R. Walker, A. A. Crawford, L. Colodro-Conde, S. E. Medland, N. G. Martin, and M. Rietschel 2017. Hair cortisol in twins: Heritability and genetic overlap with psychological variables and stress-system genes. Sci. Rep. 7:15351. https://doi.org/10.1038/s41598-017-11852-3.

Russell, E., G. Koren, M. Rieder, and S. Van Uum. 2012. Hair cortisol as a biological marker of chronic stress: Current status, future directions and unanswered questions. Psychoneuroendocrinology 37:589-601. https://doi.org/10.1016/j.psyneuen.2011.09.009.

Shi, R. 2021a. FigureS1.tiff. figshare. Figure. https://doi.org/https:// doi.org/10.6084/m9.figshare.13543673.v1.

Shi, R. 2021b. FigureS2.tiff. figshare. Figure. https://doi.org/https:// doi.org/10.6084/m9.figshare.13543670.v1

Smith, P. K., R. L. Krohn, G. T. Hermunson, K. Mallia, F. H. Gartner, M. D. Provenzan, E. K. Fujimoto, N. M. Goeke, B. J. Olson, and D. C. Klerk. 1985. Measurements of protein using bicinchoninic acid. Anal. Biochem. 15:7685.

St-Pierre, N. R., B. Cobanov, and G. Schnitkey. 2003. Economic losses from heat stress by US livestock industries. J. Dairy Sci. 86:E52E77. https://doi.org/10.3168/jds.S0022-0302(03)74040-5.

Suomi, S. J. 2006. Risk, resilience, and gene x environment interactions in rhesus monkeys. Ann. N. Y. Acad. Sci. 1094:52-62. https: //doi.org/10.1196/annals.1376.006.

Tamanini, C., N. Giordano, F. Chiesa, and E. Seren. 1983. Plasma cortisol variations in the stallion by mating. Acta Endocrinol. (Copenh.) 102:44750. https://doi.org/10.1530/acta.0.1020447.

Thomson, S., G. Koren, L. A. Fraser, M. Rieder, T. C. Friedman, and S. H. M. Van Uum. 2010. Hair analysis provides a historical record of cortisol levels in Cushing's syndrome. Exp. Clin. Endocrinol. Diabetes 118:133-138. https://doi.org/10.1055/s-0029-1220771.

Tiwari, R. V., P. Parajuli, and P. W. Sylvester. 2015. $\gamma$-Tocotrienolinduced endoplasmic reticulum stress and autophagy act concur- 
rently to promote breast cancer cell death. Biochem. Cell Biol. 93:306-320. https://doi.org/10.1139/bcb-2014-0123.

Tucker-Drob, E. M., A. D. Grotzinger, D. A. Briley, L. E. Engelhardt, F. D. Mann, M. Patterson, C. Kirschbaum, E. K. Adam, J. A. Church, J. L. Tackett, and K. P. Harden. 2017. Genetic influences on hormonal markers of chronic hypothalamic-pituitary-adrenal function in human hair. Psychol. Med. 47:1389-1401. https://doi .org/10.1017/S0033291716003068.

Uetake, K., S. Morita, N. Sakagami, K. Yamamoto, S. Hashimura, and T. Tanaka. 2017. Hair cortisol levels of lactating dairy cows in cold- and warm-temperate regions in Japan. Anim. Sci. J. 89:494497. https://doi.org/10.1111/asj.12934.

Venables, W. N., and B. D. Ripley. 2002. Modern Applied Statistics with S. Statistics and Computing. Springer New York.

Wennig, R. 2000. Potential problems with the interpretation of hair analysis results. Forensic Sci. Int. 107:5-12. https://doi.org/10 .1016/S0379-0738(99)00146-2.

West, J. W., B. G. Mullinix, and J. K. Bernard. 2003. Effects of hot, humid weather on milk temperature, dry matter intake, and milk yield of lactating dairy cows. J. Dairy Sci. 86:232-242. https://doi .org/10.3168/jds.S0022-0302(03)73602-9.

Wüst, S., I. Federenko, D. H. Hellhammer, and C. Kirschbaum. 2000 Genetic factors, perceived chronic stress, and the free cortisol response to awakening. Psychoneuroendocrinology 25:707-720. https://doi.org/10.1016/S0306-4530(00)00021-4.
You, Q., N. A. Karrow, H. Cao, A. Rodriguez, B. A. Mallard, and H. J. Boermans. 2008. Variation in the ovine cortisol response to systemic bacterial endotoxin challenge is predominantly determined by signalling within the hypothalamic-pituitary-adrenal axis. Toxicol. Appl. Pharmacol. 230:1-8. https://doi.org/10.1016/ j.taap.2008.01.033.

Zhang, Q., Z. Chen, S. Chen, Y. Xu, and H. Deng. 2017. Intraindividual stability of cortisol and cortisone and the ratio of cortisol to cortisone in saliva, urine and hair. Steroids 118:61-67. https://doi .org/10.1016/j.steroids.2016.12.008.

Zimbelman, R. B., R. J. Collier, and M. L. Eastridge. 2011. Feeding strategies for high-producing dairy cows during periods of elevated heat and humidity. Pages 111-126 in Proc. 2011 Tri-state Dairy Nutrition Conf. Fort Wayne, IN. Purdue University Press.

\section{ORCIDS}

R. Shi ৫ https://orcid.org/0000-0002-0047-1262

A. Sammad ๑ https://orcid.org/0000-0002-9171-795X

H. Luo (ํ) https://orcid.org/0000-0001-6211-3834

G. Guo (ㄱ https://orcid.org/0000-0001-8677-6325

Yachun Wang (i) https://orcid.org/0000-0003-3629-2802 